\title{
Rapid monitoring of health services use following a policy to switch patients from originator to biosimilar etanercept-a cohort study in British Columbia
}

\author{
Anat Fisher* ${ }^{*}$, Jason D. Kim (1D, Greg Carney 10 and Colin Dormuth 10
}

\begin{abstract}
Background: Drug coverage policies that incentivize switching patients from originator to biosimilar products may result in significant health care savings. Our study aimed to detect early impacts on health services utilization following a mandated switch from originator to biosimilar etanercept in British Columbia (BC), Canada.

Methods: We conducted a prospective, population-based cohort study using linked administrative health data from BC (2010-2020). The policy cohort consisted of patients with inflammatory arthritis who used originator etanercept in 2019, prior to BC's Biosimilars Initiative switching policy. Three historical cohorts included patients with inflammatory arthritis who used originator etanercept in the years 2016, 2017, and 2018. We compared the daily cumulative incidences of drug refills and outpatient and inpatient services between the policy and historical cohorts. A likelihood ratio sustained ( $\geq 31$ days) at 7.1 or higher compared with the null hypothesis was chosen a priori as a threshold for a potential impact of the policy.

Results: Each cohort contained between 1694 and 1963 patients. We detected several potential impacts: 1) a transient increase in etanercept refills between months three and eight (cumulative incidence difference of $+3.0 \%$ ); 2) an anticipated increase in visits to physicians of any specialty between months three and eight $(+2.6 \%)$; and 3$)$ an anticipated increase in visits to a rheumatologist from the end of month three onwards $(+12.8 \%)$. The policy had no impact on incidences of switching to a different biologic antirheumatic drug, visits to emergency departments, or admissions to hospitals.
\end{abstract}

Conclusions: Only transient and/or anticipated increases in drug refills and physician visits were observed during the study period. Additional research on clinical outcomes is recommended to strengthen the evidence that no longterm unintended negative health impacts are associated with BC's Biosimilars Initiative [switching policy].

Keywords: Arthritis, psoriatic, Arthritis, rheumatoid, Biosimilar pharmaceuticals, Drug switching, Etanercept, Health policy, Insurance coverage, Spondylitis, ankylosing

*Correspondence: anat.fisher@ubc.ca

Department of Anesthesiology, Pharmacology and Therapeutics,

University of British Columbia, 2176 Health Sciences Mall, Vancouver, BC V6T 1Z3, Canada

\section{Background}

Biologic disease-modifying anti-rheumatic drugs (bDMARDs), such as tumor necrosis factor inhibitors, have revolutionized the management of serious health conditions over the last two decades. This therapy has also raised health care costs significantly [1]. Originator 
etanercept (trade name Enbrel) was the first tumor necrosis factor inhibitor approved to treat patients with rheumatoid arthritis in Canada and the United States. Etanercept is widely prescribed to treat inflammatory arthritis, such as rheumatoid arthritis, psoriatic arthritis, and axial spondyloarthritis [2-4]. Following the recent patent expiration of originator etanercept, the more affordable biosimilar versions of etanercept are available. Switching patients from originator etanercept to its biosimilars as part of routine clinical practice may result in significant public and private drug cost savings $[5,6]$. The biosimilar products Brenzys and Erelzi were approved by Health Canada in August 2016 and April 2017 respectively [7]. Both have demonstrated no clinically meaningful differences in quality, efficacy, safety, or immunogenicity compared with originator etanercept in clinical trials [8] or in analyses of real-world data [9]. Treatment persistence with biosimilar versions of etanercept was comparable or longer than with originator etanercept $[10,11]$. Even with increasing evidence that switching to biosimilar products is not associated with negative effects on patient health, some patients and physicians have expressed concerns and resisted switching [12-15].

On 27 May 2019 the British Columbia (BC) Ministry of Health implemented Phase 1 of the Biosimilars Initiative, a drug coverage policy that required a non-medical switch from originator etanercept to its biosimilars [16]. To qualify for cost coverage by the provincial drug plan PharmaCare, patients treated with originator etanercept for rheumatoid arthritis, ankylosing spondylitis, or psoriatic arthritis were required to switch to a biosimilar etanercept. During a six-month transition period, BC PharmaCare covered the costs of originator etanercept only for patients with continuous approval of coverage. After the transition period, only the biosimilars were covered, unless a medical exemption was submitted by a physician.

The BC Ministry of Health requested real-time monitoring of the impact of the Biosimilars Initiative on health services utilization. This involved examining the use of health services such as emergency department visits and drugs such as nonsteroidal anti-inflammatory drugs (NSAIDs) or oral steroids, which served as proxies for disease activity in this analysis $[17,18]$. Previous studies assessed changes in health services utilization following the launch of a non-medical switching policy for bDMARDs based on estimates from physician surveys $[19,20]$ or real-world data on etanercept switching [21-24]. These methodologies require significant resources and are limited to a single analysis, which is often delayed. The aim of this rapid monitoring analysis was to detect signals of intended and unintended impacts on health services utilization over a one-year period following the launch of the Biosimilars Initiative for patients treated with originator etanercept $[25,26]$. Our study was designed to detect potential signals of unintended negative impacts in an entire population, and not to accept or reject a hypothesis of harm in the presence of a sampling error. If negative impacts were detected, additional analysis was considered. Unintended negative impacts of the policy are, for example, a decrease in refilling etanercept or an increase in switching to other bDMARDs, emergency department visits, or hospitalizations. Intended impacts include an increase in the percentage use of biosimilars in etanercept utilization and an increase in visits to physicians.

\section{Methods}

\section{Setting}

The Canadian province of British Columbia has a universal health system that provides access to medically necessary health services, such as physician and hospital services. In addition, eligible prescription drugs, certain medical supplies, and pharmacy services are covered under the provincial drug plan, PharmaCare. $\mathrm{BC}$ residents, regardless of age and income, are eligible to register for PharmaCare coverage. The largest plan, Fair PharmaCare, is income-based, i.e., patients and families are eligible for cost subsidies after reaching their annual deductible level [27].

\section{Study design and data source}

We conducted rapid monitoring of health services utilization $[25,26]$ using a prospective cohort study design and administrative data from the BC Ministry of Health. The data included population-based, province-wide information on prescriptions filled in all community pharmacies, diagnoses recorded in visits to physicians and other providers, hospital and emergency department records, and medical services registration data. Data were linked using anonymized identifiers. We had no access to data of individuals covered directly by federal health care programs [28] and beneficiaries of the BC First Nations Health Authority Health Benefits Program [29]. Data were analyzed using Oracle SQL Developer and SAS (version 9.4, SAS Institute Inc., Cary, NC, USA) software.

\section{Study cohorts}

We assembled four cohorts of users of the originator etanercept from a source population of individuals enrolled in the provincial health plan. The policy cohort was constructed from all patients who used originator etanercept between 27 November 2018 and 26 May 2019, i.e., during the six months before the launch of the Biosimilars Initiative. Similarly, patients were included in 
the three historical cohorts if they refilled a prescription for the originator etanercept in the six months before 27 May in the prior years of 2016, 2017, and 2018. Cohort entry occurred on 27 May of each year. We excluded patients who were not targeted by the policy, i.e., patients with psoriasis, those who had discontinued or switched away from originator etanercept, and patients whose drug costs were not covered by PharmaCare. We also excluded patients with short follow-up ( $<30$ days). For details on exclusion criteria, please refer to Additional file 1: Table S1.

\section{Exposure and outcomes}

Patients in the policy cohort were considered exposed to the policy, while patients in the three historical cohorts served as controls. The main outcomes consisted of cumulative incidence, updated daily, of drug and health services use: refills for etanercept (originator or biosimilar); switching to biosimilar etanercept (for the policy cohort only); switching to another bDMARD or a targeted synthetic DMARD (tsDMARD); office visits to a physician (outpatient setting, any specialty); office visits to a rheumatologist (outpatient setting); visits to an emergency department; and hospital admissions. Secondary outcomes included the average cumulative dose of etanercept (originator or biosimilar); and the average cumulative days' supply for each of the following therapeutic groups: conventional synthetic DMARDs (csDMARDs), NSAIDs, or oral steroids. The full list of drugs is included in Additional file 1: Table S2.

\section{Statistical analysis}

For the main outcomes, we computed daily cumulative incidence differences between the policy cohort and the average of the historical cohorts. In the absence of an effect of the Biosimilars Initiative, the cumulative incidence trend for the policy cohort was expected to follow the average cumulative incidence trends for the historical cohorts, i.e., the expected cumulative incidence difference was zero. Since the cumulative incidence differences were measured daily and updated monthly, we used likelihood ratios to assess the "strength" of cumulative incidence differences to facilitate their interpretation as signals versus noise. Unlike test statistics, the interpretation of a likelihood ratio remains the same regardless of how many times the data are updated [30]. The likelihood ratio denoted the likelihood of the observed cumulative incidence difference relative to no difference. For our analysis, a cumulative incidence difference was considered a signal if the likelihood ratio for the observed difference versus no difference was sustained at a threshold of $7.1\left(e^{z=1.96}\right)$ or higher for 31 days or longer [25]. This means that the null hypothesis (i.e., cumulative incidence difference of zero) was 7.1-fold less likely than the observed difference. Details of the likelihood ratio calculation are available from the study protocol [25]. Secondary outcomes were descriptive; we plotted cumulative quantity per patient over time of follow-up.

\section{Results}

Biosimilar uptake in British Columbia

During the six-month transition period, we observed a sharp increase in the percentage of prescriptions for the

Table 1 Identification of historical and policy cohorts: eligible, excluded, and included users of originator etanercept

\begin{tabular}{|c|c|c|c|c|}
\hline & \multicolumn{4}{|l|}{ Cohort, n (\%) } \\
\hline & \multicolumn{3}{|l|}{ Historical } & \multirow{2}{*}{$\begin{array}{l}\text { Policy } \\
2019\end{array}$} \\
\hline & 2016 & 2017 & 2018 & \\
\hline Identification period & $\begin{array}{l}\text { November } 28, \\
2015 \text { to May } 26, \\
2016^{a}\end{array}$ & $\begin{array}{l}\text { November 27, } \\
2016 \text { to May 26, } \\
2017\end{array}$ & $\begin{array}{l}\text { November } 27, \\
2017 \text { to May } 26, \\
2018\end{array}$ & $\begin{array}{l}\text { November 27, } \\
2018 \text { to May 26, } \\
2019\end{array}$ \\
\hline $\begin{array}{l}\text { Eligible prescriptions for originator etanercept (patients) during the } \\
\text { identification period }\end{array}$ & $11,360(2423)$ & $11,952(2476)$ & $11,274(2266)$ & $10,374(2065)$ \\
\hline \multicolumn{5}{|l|}{$\begin{array}{l}\text { Exclusion criteria, number of patients excluded (\% of patients } \\
\text { identified) })^{b}\end{array}$} \\
\hline Diagnosis of psoriasis & $112(4.6)$ & $88(3.6)$ & $81(3.6)$ & $69(3.3)$ \\
\hline Low compliance/discontinuers & $283(11.7)$ & $276(11.1)$ & $245(10.8)$ & $220(10.7)$ \\
\hline Switchers & $19(0.8)$ & $22(0.9)$ & $10(0.4)$ & $8(0.4)$ \\
\hline Short follow-up & $21(0.9)$ & $20(0.8)$ & $16(0.7)$ & $12(0.6)$ \\
\hline No PharmaCare coverage & $110(4.5)$ & $107(4.3)$ & $91(4.0)$ & $62(3.0)$ \\
\hline Final number of etanercept users included in the cohort & 1878 & 1963 & 1823 & 1694 \\
\hline
\end{tabular}

a 2016 was a leap year

${ }^{b}$ For details on exclusion criteria, please refer to Additional file 1: Table S1 
Table 2 Demographic characteristics and diagnosis of users of the originator etanercept, by cohort

\begin{tabular}{|c|c|c|c|c|}
\hline & \multicolumn{4}{|l|}{ Cohort } \\
\hline & Historical & & & Policy \\
\hline Demographic & $2016(n=1878)$ & $2017(n=1963)$ & $2018(n=1823)$ & $2019(n=1694)$ \\
\hline Age median (range), years & $59.0(3.0-94.0)$ & $59.0(3.0-95.0)$ & $60.0(3.0-96.0)$ & $61.0(3.0-97.0)$ \\
\hline Female & $1181(62.9)$ & $1232(62.8)$ & $1126(61.8)$ & $1017(60.0)$ \\
\hline \multicolumn{5}{|l|}{ Diagnosis $^{a}$} \\
\hline Rheumatoid arthritis & $1185(63.1)$ & $1230(62.7)$ & $1087(59.6)$ & $996(58.8)$ \\
\hline Juvenile rheumatoid arthritis & $49(2.6)$ & $63(3.2)$ & $62(3.4)$ & $48(2.8)$ \\
\hline Ankylosing spondylitis & $188(10.0)$ & $201(10.2)$ & $201(11.0)$ & $181(10.7)$ \\
\hline Psoriatic arthritis & $237(12.6)$ & $265(13.5)$ & $286(15.7)$ & $300(17.7)$ \\
\hline Undetermined & $219(11.7)$ & $204(10.4)$ & $187(10.3)$ & $169(10.0)$ \\
\hline More than one diagnosis & $142(7.6)$ & $142(7.2)$ & $130(7.1)$ & $118(7.0)$ \\
\hline
\end{tabular}

Numbers represent patients (\% of cohort) unless otherwise specified

${ }^{a}$ Identified based on at least five visits to a physician or emergency department, or at least one discharge from hospital with a diagnosis code for one of the four conditions in the five years before cohort entry. Rheumatoid arthritis: International Classification of Diseases (ICD)-9 code 714 (except 714.3, 714.4 ); ICD-10 codes M05, M06 (age at first diagnosis > 18 years). Juvenile rheumatoid arthritis: ICD-9 codes 714, 714.3; ICD-10 codes M05, M06, M08 (age at first diagnosis $\leq 18$ years). Ankylosing spondylitis: ICD-9 code 720 (except 720.1-720.9); ICD-10 code M45. Psoriatic arthritis: ICD-9 code 696.0; ICD-10 code M07

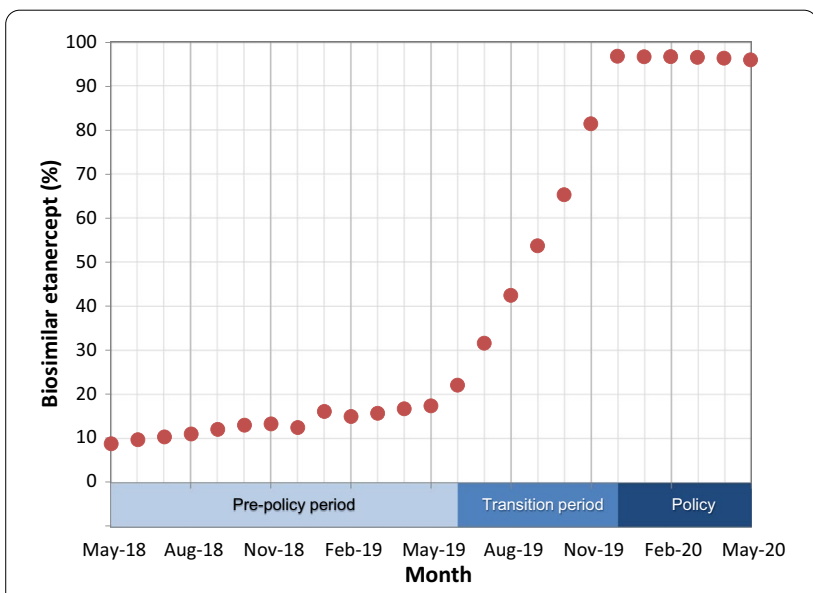

Fig. 1 Prescriptions for biosimilar etanercept-percentage of all etanercept prescription refills covered by PharmaCare, by month

biosimilars among all etanercept prescription refills covered by PharmaCare, from $17.3 \%$ (349 of 2016 prescriptions) in May 2019 to $96.9 \%$ (1887 of 1948 prescriptions) in December 2019 (Fig. 1).

\section{Study cohorts}

For the rapid monitoring cohorts, we identified between 2065 and 2476 patients with refills for originator etanercept during the six-month identification periods ending on 26 May of each year (Table 1). We excluded between $10.7 \%$ and $11.7 \%$ (220-283) of the patients in each cohort because they discontinued treatment. After applying additional exclusion criteria, the final historical cohorts included between 1823 and 1963 patients with inflammatory arthritis treated with originator etanercept; the policy cohort contained 1694 patients. Among 2655 patients included in this project, $24 \%$ (626) were included in one cohort only, and 40\% (1067) were included in all four cohorts. The median age of the patients in each cohort ranged from 59 to 61 years, and most were female (60.0\%-62.9\%) (Table 2). The most common diagnosis was rheumatoid arthritis $(58.8 \%-63.1 \%)$, followed by psoriatic arthritis (12.6\%-17.7\%).

\section{Main outcomes}

For drug utilizations, we detected a transient increase (up to $+3.0 \%$ ) in the cumulative incidence difference in the first and second refills of etanercept during followup (Fig. 2). The likelihood ratio threshold of $>7.1$ was exceeded during days 121 to 261 for the first refill, and day 222 for the second refill. No difference was observed in the cumulative incidence of the third and the fourth refills. By the end of the six-month transition period, $65.1 \%$ (1102) of the patients in the policy cohort had switched to a biosimilar version of etanercept, and $88.1 \%$ (1493) did so by the end of the one-year follow-up period. Trends in switching to a different bDMARD were similar between the policy and historical cohorts. Between $8.2 \%$ and $9.7 \%(149-183)$ of the patients in the historical cohorts and 9.6\% (162) of the patients in the policy cohort switched to a different bDMARD by the end of the one-year follow-up.

For visits to physicians (Fig. 3), a transient increase of up to $+0.9 \%$ was observed in the cumulative incidence difference in first visits to a physician (any 


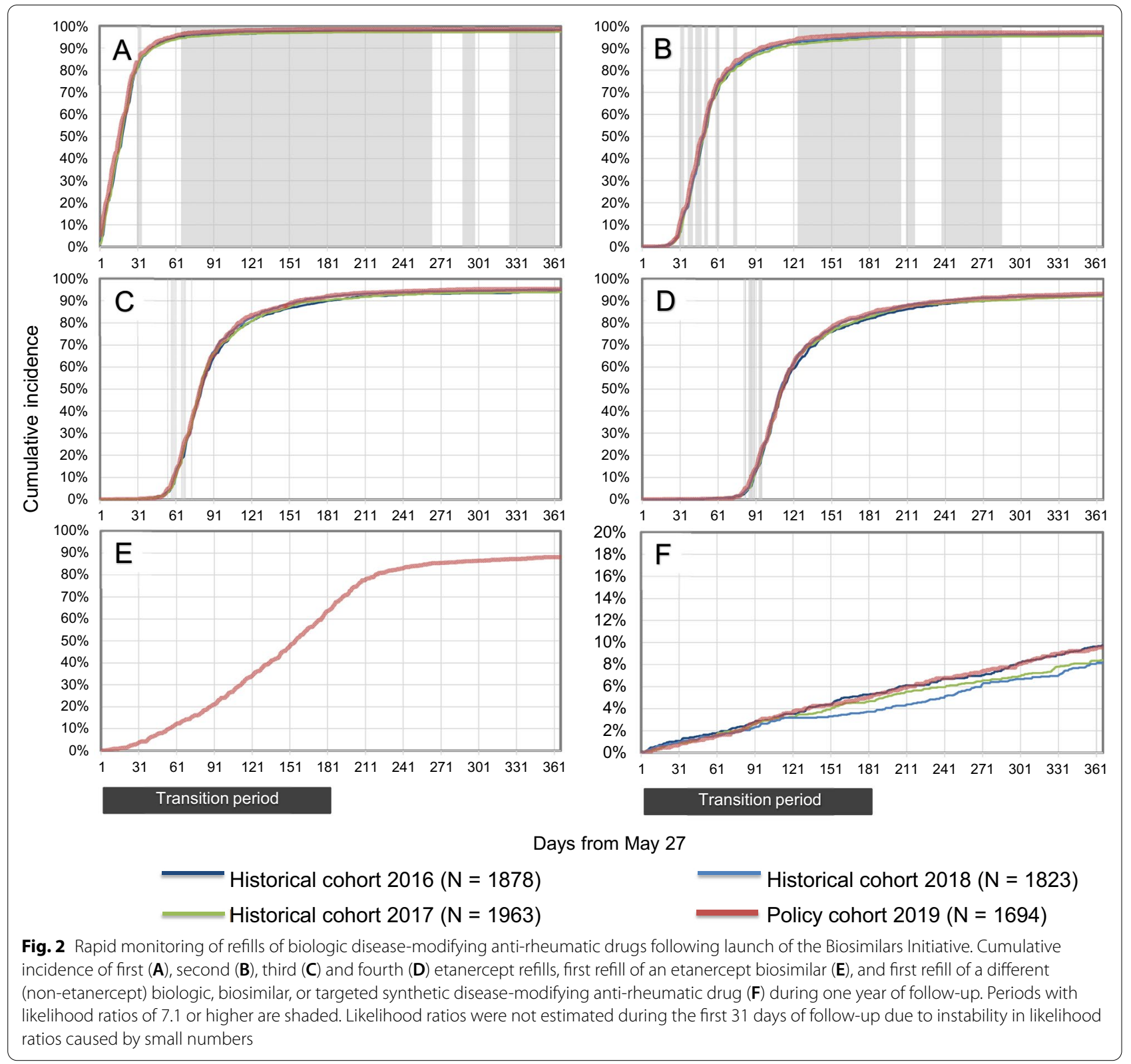

specialty, days 168 to 208 of follow-up). A transient increase of up to $+1.7 \%$ was detected in second visits (days 148 to 249). No difference was detected in third visits to a physician. Finally, we observed a transient increase of up to $+2.6 \%$ in the cumulative incidence difference in fourth visits to a physician (days 171 to 243). Differences in visits to a rheumatologist reached the predefined threshold. The maximal cumulative incidence difference for the first visit to a rheumatologist was $+12.8 \%$ (from day 86 onwards). The maximal difference for second visits to a rheumatologist was $+12.7 \%$ (from day 111 onwards). No difference was observed in the cumulative incidence of visits to an emergency department or admissions to a hospital between the policy cohort and the three historical cohorts (Fig. 4).

\section{Secondary outcomes}

Patterns of average cumulative quantity of etanercept (originator or biosimilar) dispensed per patient, and average cumulative number of days on csDMARDs, oral steroids, or NSAIDs were similar or lower in the policy cohort compared with the historical cohorts (Additional file 1: Figs. S1-S4). 


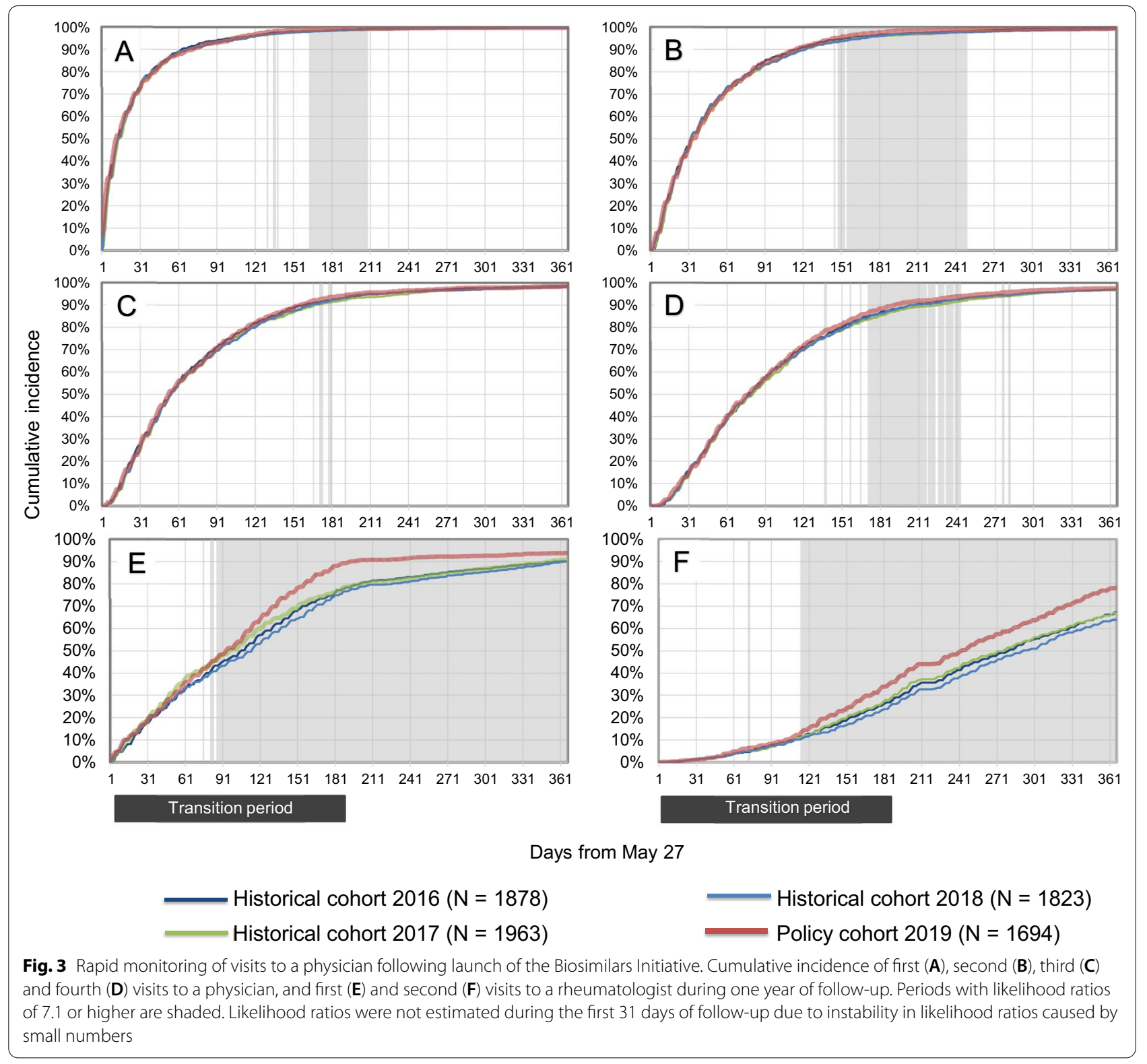

\section{Discussion}

In this prospective study, we observed an intended increase in the use of biosimilars of etanercept following the launch of the Biosimilars Initiative as most users of originator etanercept switched to the biosimilar products during the six-month transition period. In the monitoring of health services utilization using a pre-defined likelihood ratio threshold of 7.1, we observed anticipated changes, such as an increase in visits to a physician (any specialty) and to a rheumatologist [19, 20, 22, 31]. Other changes were either minor and transient, i.e., a transient increase in etanercept refills, or the direction of the change in utilization suggested a possible benefit.
Specifically, patients in the policy cohort had fewer days on csDMARDs, oral steroids, and NSAIDs, which may suggest better control of disease severity $[17,18]$.

This study has several strengths. First, we were able to monitor the policy and detect change in health services utilization as soon as data were available. We provided policymakers with monthly reports, each with only a onemonth lag time. Using likelihood ratios instead of test statistics allowed us to update the analyses and compare utilization daily without having to correct for repeated measures and prior knowledge. A particular strength of this study is the use of a province-wide, populationbased dataset that includes data collected systematically 

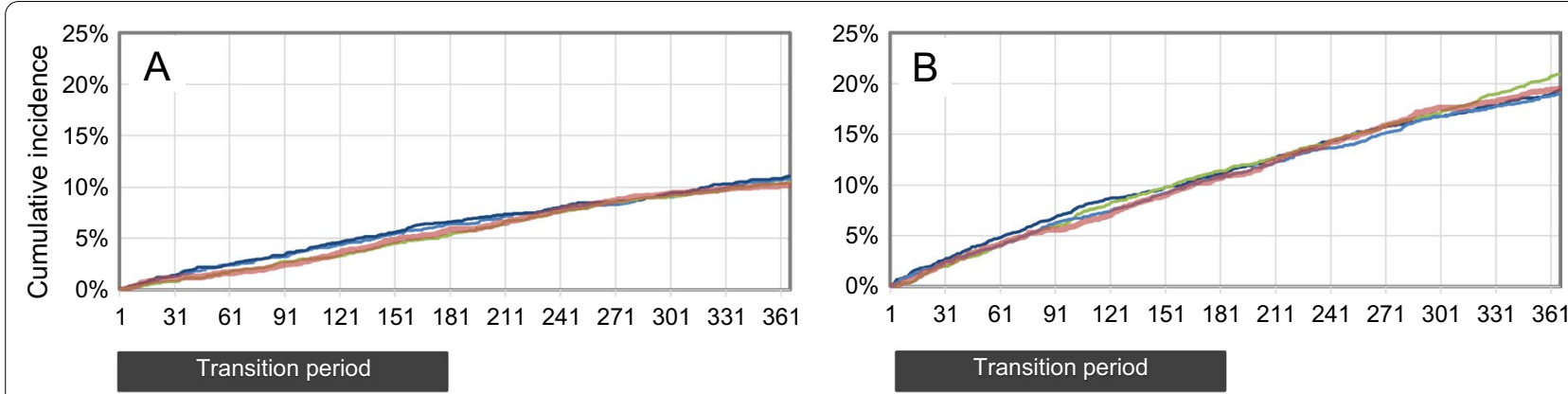

Days from May 27
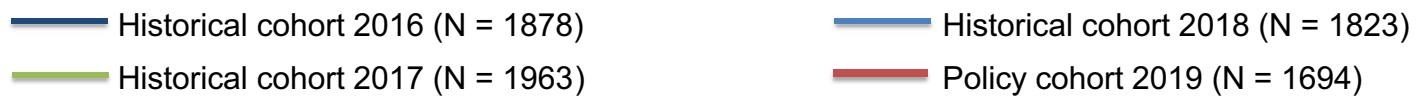

Fig. 4 Rapid monitoring of hospital admissions and emergency department visits following launch of the Biosimilars Initiative. Cumulative incidence of admission to hospital $(\mathbf{A})$ and visit to an emergency department (B) during one year of follow-up. No periods with likelihood ratios of 7.1 or higher were detected

and prospectively. Inherent limitations of this study are the absence of a control for possible differences between cohorts, as well as possible correlation between observations of patients included in more than one cohort. Controlling for covariance between cohorts could have caused the likelihood ratios to increase, and cumulative incidence differences with likelihood ratios less than 7.1 would have triggered a signal. The use of administrative data for research also has limitations, including inaccuracies in diagnosis or adherence to drugs, and the absence of information on predictors such as disease severity or smoking.

Several other studies examined the effect of a nonmedical switch from originator etanercept to a biosimilar, many of which focused on treatment discontinuation $[9,10,21,23,24,32-38]$. A single study from Denmark examined the change in health services utilization after implementation of a mandatory non-medical switching policy for etanercept [22]. The Danish study found that the use and costs of outpatient services increased after switching patients from originator etanercept to a biosimilar, whereas costs of admissions and drugs decreased. Increases in visits to a physician were also observed in infliximab studies from Italy and Turkey [31, 39]. A cohort study from Italy found an $83 \%$ increase in visits to specialists, especially rheumatologists, in patients who switched to the biosimilar infliximab [31]. In a crude analysis from Turkey, health services costs were significantly higher in outpatient settings $(P=0.005)$ for patients who switched to biosimilar infliximab compared with those who continued with originator infliximab [39]. In our study, we found that switching from the originator etanercept to biosimilar products was associated with a transient increase in visits to a physician of any specialty, which diminished within a few weeks of the end of the transition period. It is possible that this increase in physician visits was in patients seeking to discuss treatment options before the switch. An increase in visits after switching, on the other hand, may have indicated unintended negative impacts of a policy. Further research with a design similar to the Danish studies [22, 40, 41] could provide a better understanding of this change in British Columbia.

\section{Conclusions}

Using rapid monitoring of drug and health services utilization, we were able to provide policymakers in British Columbia with real-time data on the impact of the Biosimilars Initiative for users of etanercept. We did not find permanent unintended changes in health services utilization, which suggests that switching to the biosimilar etanercept had minimal impacts on patient health. Additional research on clinical outcomes is recommended to strengthen the evidence that no long-term unintended negative health impacts are associated with switching from originator etanercept to its biosimilars.

\section{Abbreviations}

BC: British Columbia; bDMARD: Biologic disease-modifying anti-rheumatic drug; CSDMARD: Conventional synthetic disease-modifying anti-rheumatic drug; NSAIDs: Nonsteroidal anti-inflammatory drugs; tsDMARD: Targeted synthetic disease-modifying anti-rheumatic drug.

\section{Supplementary Information}

The online version contains supplementary material available at https://doi. org/10.1186/s41927-021-00235-X. 
Additional file 1. Supplementary Table 1. Cohorts construction: exclusion criteria. Supplementary Table 2 . Drugs by therapeutic group. Supplementary Figure 1. Cumulative quantity of etanercept (originator or biosimilar) dispensed (mg per patient) over the follow-up period, by cohort. Supplementary Figure 2. Cumulative number of days on conventional synthetic disease modifying anti-rheumatic drugs (csDMARDs) per patient, over the follow-up period, by cohort. Supplementary Figure 3. Cumulative number of days on oral steroids per patient, over the follow-up period, by cohort. Supplementary Figure 4. Cumulative number of days on nonsteroidal anti-inflammatory drugs (NSAIDs) per patient, over the follow-up period, by cohort.

\section{Acknowledgements}

We thank Tracey Hooper and Ellen Reynolds for editing assistance. The BC Ministry of Health approved access to and use of $\mathrm{BC}$ data facilitated by Population Data BC for this study. All inferences, opinions, and conclusions drawn in this manuscript are those of the authors, and do not reflect the opinions or policies of the Data Stewards. British Columbia data sources were as follows (https://www2.gov.bc.ca/gov/content/health/conducting-health-resea rch-evaluation/data-access-health-data-central): British Columbia Ministry of Health [creator] (2020): Medical Services Plan (MSP) Payment Information File. BC Ministry of Health [publisher]. MOH (2019); British Columbia Ministry of Health [creator] (2020): PharmaNet. BC Ministry of Health [publisher]. Data Stewardship Committee (2019); Canadian Institute for Health Information [creator] (2020): National Ambulatory Care Reporting System. BC Ministry of Health [publisher]. MOH (2019); Canadian Institute for Health Information [creator] (2020): Discharge Abstract Database (Hospital Separations). BC Ministry of Health [publisher]. MOH (2019); British Columbia Ministry of Health [creator] (2020): Consolidation File (MSP Registration \& Premium Billing). BC Ministry of Health [publisher]. MOH (2019).

\section{Authors' contributions}

AF, CD and GC made substantial contributions to the conception and the design of the work; AF and JDK were responsible for the acquisition and analysis of the data; $\mathrm{AF}, \mathrm{JDK}, \mathrm{GC}$, and $\mathrm{CD}$ contributed to the interpretation of data. AF and JK prepared the tables and figures of the manuscript. AF wrote a first draft of the manuscript. AF, JDK, GC and CD reviewed and approved the manuscript. All authors have agreed both to be personally accountable for the author's own contributions and to ensure that questions related to the accuracy or integrity of any part of the work, even ones in which the author was not personally involved, are appropriately investigated, resolved, and the resolution documented in the literature. All authors read and approved the final manuscript.

\section{Funding}

This project was funded by the British Columbia Ministry of Health, Pharmaceutical, Laboratory \& Blood Services Division as part of a plan for evaluating the impact of a change in coverage for biosimilar medications. All inferences, opinions, and conclusions drawn in this manuscript are those of the authors, and do not reflect the opinions or policies of the British Columbia Ministry of Health.

\section{Availability of data and materials}

The authors do not have permission to share data from this study. The data that support the findings of this study are available from PopData BC (https:// www.popdata.bc.ca/), but restrictions apply to the availability of these data, which were used under licence for the current study, and so are not publicly available.

\section{Declarations}

\section{Ethics approval and consent to participate}

All procedures performed in this study were in accordance with the ethical standards of the institutional and/or national research committee and with the 1964 Declaration of Helsinki and its later amendments or comparable ethical standards. The study protocol was approved by the University of British Columbia Clinical Research Ethics Board (UBC CREB number H19-02377).

\section{Consent for publication}

Not applicable.

\section{Informed consent}

The consent was waived by the University of British Columbia Clinical Research Ethics Board (UBC CREB Number H19-02377).

\section{Standards of reporting}

The study is compliant with the STROBE standard of reporting checklist for observational studies and the SAMPL Guidelines for reporting of basic statistical analyses.

\section{Competing interests}

The authors declare that they have no competing interests.

Received: 12 August 2021 Accepted: 11 October 2021

Published online: 27 January 2022

\section{References}

1. Canada, Patented Medicine Prices Review Board. Biologics in Canada. Part 1: Market Trends, 2018. Canada, Patented Medicine Prices Review Board. Biologics in Canada. Part 1: Market Trends, 2018. 2020. https://www. canada.ca/en/patented-medicine-prices-review/services/reports-studies/ biologics-part1-market-trends.html. Accessed 27 Jan 2021.

2. Immunex Corporation. Enbrel Product information. In: Health Canada Drug Product Database online query. 2018. https://health-products. canada.ca/dpd-bdpp/info.do?lang=en\&code $=66735$. Accessed 15 Dec $15,2020$.

3. Chadwick L, Zhao S, Mysler E, Moots RJ. Review of biosimilar trials and data on etanercept in rheumatoid arthritis. Curr Rheumatol Rep. 2018. https://doi.org/10.1007/s11926-018-0799-0.

4. Zhao S, Mysler E, Moots RJ. Etanercept for the treatment of rheumatoid arthritis. Immunotherapy. 2018. https://doi.org/10.2217/imt-2017-0155.

5. Mulcahy AW, Hlavka JP, Case SR. Biosimilar cost savings in the United States: initial experience and future potential. RAND health Q. 2018;7(4):3.

6. Tesar T, Golias P, Kobliskova Z, Wawruch M, Kawalec P, Inotai A. Potential cost-savings from the use of the biosimilars in Slovakia. Front public health. 2020. https://doi.org/10.3389/fpubh.2020.00431.

7. Government of Canada. Notice of Compliance Database. https://healthproducts.canada.ca/noc-ac/index-eng.jsp. Accessed 11 Aug 2021.

8. Barbier L, Ebbers HC, Declerck P, Simoens S, Vulto AG, Huys I. The Efficacy, safety, and immunogenicity of switching between reference biopharmaceuticals and biosimilars: a systematic review. Clin Pharmacol Ther. 2020. https://doi.org/10.1002/cpt.1836.

9. Ebbers HC, Pieper B, Issa A, Addison J, Freudensprung U, Rezk MF. Realworld evidence on etanercept biosimilar SB4 in etanercept-naïve or switching patients: a systematic review. Rheumatol Ther. 2019. https:// doi.org/10.1007/s40744-019-00169-4.

10. Fleischmann R, Jairath V, Mysler E, Nicholls D, Declerck P. Nonmedical switching from originators to biosimilars: Does the nocebo effect explain treatment failures and adverse events in rheumatology and gastroenterology? Rheumatol Ther. 2020. https://doi.org/10.1007/ s40744-019-00190-7.

11. Moura CS, Choquette D, Coupal L, Schieir O, Valois MF, Bykerk V, Boire G, Maksymowych WP, Bernatsky S. Persistence in rheumatoid arthritis patients on biosimilar and bio-originator etanercept: a pooled analysis of pan-Canadian cohorts [abstract]. ARD. 2020;79(Suppl 1):306-7.

12. Wiland P, Batko B, Brzosko M, Kucharz EJ, Samborski W, Świerkot J, WięsikSzewczyk E, Feldman J. Biosimilar switching — current state of knowledge. Reumatologia. 2018. https://doi.org/10.5114/reum.2018.77975.

13. Halimi V, Daci A, Ancevska Netkovska K, Suturkova L, Babar Z, Grozdanova A. Clinical and regulatory concerns of biosimilars: a review of literature. Int J Environ Res Public Health. 2020. https://doi.org/10.3390/ijerph 1716 5800.

14. Murdoch B, Caulfield T. The law and ethics of switching from biologic to biosimilar in Canada. JCAG. 2020. https://doi.org/10.1093/jcag/gwz043.

15. Numan S, Faccin F. Non-medical switching from originator tumor necrosis factor inhibitors to their biosimilars: systematic review of randomized 
controlled trials and real-world studies. Adv Ther. 2018. https://doi.org/10. 1007/s12325-018-0742-9.

16. Government of British Columbia, Ministry of Health. Biosimilars Initiative launched in BC PharmaCare news letter Edition 19-003. In: Government of British Columbia, Ministry of Health. 2019. https://www2.gov.bc.ca/ assets/gov/health/health-drug-coverage/pharmacare/newsletters/ news19-003.pdf. Accessed 29 Jun 2021.

17. Chandran U, Reps J, Stang PE, Ryan PB. Inferring disease severity in rheumatoid arthritis using predictive modeling in administrative claims databases. PLoS ONE. 2019. https://doi.org/10.1371/journal.pone.02262 55.

18. Sauer BC, Teng C, Accortt NA, Burningham Z, Collier D, Trivedi M, Cannon GW. Models solely using claims-based administrative data are poor predictors of rheumatoid arthritis disease activity. Arthritis Res Ther. 2017. https://doi.org/10.1186/s13075-017-1294-0.

19. Gibofsky A, Skup M, Yang M, Mittal M, Macaulay D, Ganguli A. Short-term costs associated with non-medical switching in autoimmune conditions. Clin Exp Rheumatol. 2019:37(1):97-105 (PMID: 29998841)

20. Tarallo M, Onishchenko K, Alexopoulos ST. Costs associated with nonmedical switching from originator to biosimilar etanercept in patients with rheumatoid arthritis in the UK. J Med Econ. 2019. https://doi.org/10. 1080/13696998.2019.1652183

21. Di Giuseppe D, Frisell T, Ernestam S, ForsbladD'Elia H, Lindqvist E, Lindstrom U, Sjowall C, Askling J. Uptake of rheumatology biosimilars in the absence of forced switching. Expert Opin Biol Ther. 2018. https://doi.org/ 10.1080/14712598.2018.1458089.

22. Glintborg B, Ibsen R, Bilbo REQ, Lund Hetland M, Kjellberg J. Does a mandatory non-medical switch from originator to biosimilar etanercept lead to increase in healthcare use and costs? A Danish register-based study of patients with inflammatory arthritis. RMD Open. 2019. https://doi.org/10. 1136/rmdopen-2018-000710.

23. Glintborg B, Loft AG, Omerovic E, Hendricks O, Linauskas A, Espesen J, Danebod K, Jensen DV, Nordin H, Dalgaard EB, Chrysidis S, Kristensen S, Raun JL, Lindegaard H, Manilo N, Jakobsen S.Ho., Hansen IMJ, Dalsgaard Pedersen D, Sorensen IJ, Andersen LS, Grydehoj J, Mehnert F, Krogh NS, Hetland ML. To switch or not to switch: Results of a nationwide guideline of mandatory switching from originator to biosimilar etanercept. Oneyear treatment outcomes in 2061 patients with inflammatory arthritis from the DANBIO registry. Ann Rheum Dis. 2019; doi: https://doi.org/10. 1136/annrheumdis-2018-213474.

24. Kiltz U, Pudelko JC, Tsiami S, Baraliakos X, Braun J. Non-medical switching from reference to biosimilar etanercept-no evidence for nocebo effect: a retrospective analysis of real-life data. Clin Exp Rheumatol. 2021.

25. Dormuth CR, Fisher A, Carney G. A rapid monitoring plan following a shift in coverage from brand name to biosimilar drugs for rheumatoid arthritis in British Columbia. Pharmacoepidemiol Drug Saf. 2020. https://doi.org/ 10.1002/pds.4957.

26. Fisher A, Kim JD, Dormuth CR. Rapid monitoring of health services utilization following a shift in coverage from brand name to biosimilar drugs in British Columbia-An interim report. Pharmacoepidemiol Drug Saf. 2020. https://doi.org/10.1002/pds.5008.

27. British Columbia Ministry of Health. Fair PharmaCare Plan. In: Government of British Columbia. https://www2.gov.bc.ca/gov/content/health/healthdrug-coverage/pharmacare-for-bc-residents/who-we-cover/fair-pharm acare-plan. Accessed 12 Aug 2021

28. Canada H. Canada's Health Care System. In: Government of Canada. 2011. Health Canada. Canada's Health Care System. In: Government of Canada. 2011. https://www.canada.ca/en/health-canada/services/healthcare-system/reports-publications/health-care-system/canada.html\#a5. Accessed 25 Jan 2021

29. First Nations Health Authority. Benefits. In: https://www.fnha.ca/benefits. https://www.fnha.ca/benefits. Accessed 11 Aug 2021.

30. Goodman SN. p values, hypothesis tests, and likelihood: implications for epidemiology of a neglected historical debate. Am J Epidemiol. 1993. https://doi.org/10.1093/oxfordjournals.aje.a116700.

31. Convertino I, Lucenteforte E, Gini R, Lorenzoni V, Cazzato M, Turchetti G, Trieste L, Ferraro S, Leonardi L, Roberto G, Luciano N, Blandizzi C, Mosca M, Tuccori M. Utilisation patterns and clinical impact of the introduction of infliximab-biosimilar in Tuscany, Italy: real world evidence following the recommendation of switching for non-medical reasons. Clin Exp Rheumatol. 2020;39(4):753-62.
32. Scherlinger M, Langlois E, Germain V, Schaeverbeke T. Acceptance rate and sociological factors involved in the switch from originator to biosimilar etanercept (SB4). Semin Arthritis Rheum. 2019. https://doi.org/10. 1016/j.semarthrit.2018.07.005

33. Ditto MC, Parisi S, Priora M, Sanna S, Peroni CL, Laganà A, D'Avolio A, Fusaro E. Efficacy and safety of a single switch from etanercept originator to etanercept biosimilar in a cohort of inflammatory arthritis. Sci Rep. 2020. https://doi.org/10.1038/s41598-020-73183-0.

34. Aldasoro V, Mendizabal J, Perez Garcia S, Sada Urmeneta G, Restrepo Velez J, Del Val Del Amo, N., Paniagua Zudaire I, Gutierrez Polo R, Horcada L, Garrido Courel L, FitoManteca C. Switching from etanercept original to etanercept biosimilar. Experience in a tertiary hospital [abstract]. ARD 2020;79 Suppl 1:1434-1435

35. Luttropp K, Dalen J, Svedbom A, Dozier M, Black CM, Puenpatom A. Realworld patient experience of switching biologic treatment in inflammatory arthritis and ulcerative colitis-a systematic literature review. Patient Prefer Adherence. 2020. https://doi.org/10.2147/PPA.S238843.

36. Bruni C, Gentileschi S, Pacini G, Baldi C, Capassoni M, Tofani L, Bardelli M, Cometi L, Cantarini L, Nacci F, Vietri M, Bartoli F, Fiori G, Frediani B, Matucci-Cerinic M. The switch from etanercept originator to SB4: data from a real-life experience on tolerability and persistence on treatment in joint inflammatory diseases. Ther Adv Musculoskelet Dis. 2020. https:// doi.org/10.1177/1759720X20964031.

37. Fernandez S, Gonzalez S, Ordas Calvo C, Garcia Fernandez E, Rodriguez De Castro B, Gijon JB. Results of a mandatory switching from originator to biosimilar etanercept in 117 patients with inflammatory arthritis from a single center. ARD 2019;78 Suppl 2:1648.

38. Felis Giemza A, Chmurzynska K, Nalecz Janik J, Romanowska Prochnicka K, Swierkocka K, Wudarski M, Olesinska M. Observational study of inflammatory arthritis treatment by etanercept originator switched to an etanercept biosimilar. Reumatologia. 2019. https://doi.org/10.5114/reum. 2019.89516.

39. Phillips K, Juday T, Zhang Q, Keshishian A. Economic outcomes, treatment patterns, and adverse events and reactions for patients prescribed infliximab or CT-p13 in the Turkish population. ARD. 2017;76(Suppl 2):835.

40. Glintborg B, Sorensen IJ, Loft AG, Lindegaard H, Linauskas A, Hendricks O, Hansen IMJ, Jensen DV, Manilo N, Espesen J, Klarlund M, Grydehoj J, Dieperink SS, Kristensen S, Olsen JS, Nordin H, Chrysidis S, Dalsgaard Pedersen D, Sorensen MV, Andersen LS, Gron KL, Krogh NS, Pedersen L, Hetland ML. A nationwide non-medical switch from originator infliximab to biosimilar CT-P13 in 802 patients with inflammatory arthritis: 1-year clinical outcomes from the DANBIO registry. Ann Rheum Dis. 2017. https://doi.org/ 10.1136/annrheumdis-2016-210742.

41. Glintborg B, Sørensen J, Hetland ML. Does a mandatory non-medical switch from originator to biosimilar infliximab lead to increased use of outpatient healthcare resources? A register-based study in patients with inflammatory arthritis. RMD Open. 2018. https://doi.org/10.1136/rmdop en-2018-000710.

\section{Publisher's Note}

Springer Nature remains neutral with regard to jurisdictional claims in published maps and institutional affiliations.

Ready to submit your research? Choose BMC and benefit from:

- fast, convenient online submission

- thorough peer review by experienced researchers in your field

- rapid publication on acceptance

- support for research data, including large and complex data types

- gold Open Access which fosters wider collaboration and increased citations

- maximum visibility for your research: over 100M website views per year

At BMC, research is always in progress.

Learn more biomedcentral.com/submissions 